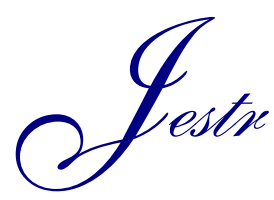

\title{
Estimation of Rotor and Stator Resistance for Induction Motor Drives using Second order of Sliding Mode Controller
}

\author{
Ritu Tak $^{1, *}$, Sudhir Y Kumar ${ }^{1}$ and Bharat Singh Rajpurohit ${ }^{2}$ \\ ${ }^{1}$ Mody University of Science \& Technology, Lakshmangarh, India \\ ${ }^{2}$ School of Computing and Electrical Engineering, IIT, Mandi, India \\ Received 11 October 2017; Accepted 20 November 2017
}

\begin{abstract}
The continues operation of vector controlled induction motor drives faces the problem of the stator and rotor resistance variation due to saturation, skin effect or in temperature variations. These resistance variations affect the controller performance. This paper illustrates about a new closed loop approach for estimation followed by compensation of the stator and rotor resistance of induction motor by using the second order sliding mode controller. The motor resistances estimated by online and the error between the actual and desired state variables of the induction motor track the sliding surface, the proposed method are based on the rigorous Lyapunov stability criteria. The simulation results show that the high frequency variation in the output waveform reduces as compared to the classical sliding mode controller and the mathematical analysis is simple to reduce the complexity faces in the higher order controller. For the estimation of the control variables of proposed algorithm only current measurement is needed and the controller is independent of the unknown parameter variation as the property of the sliding mode controller. The proposed method has been analyzed and verified with the help of Matlab/Simulink.
\end{abstract}

Keywords: Induction Motor (IM); Sliding mode controller (SMC); Parameter; Compensation; Estimation.

\section{Introduction}

Induction motor drive is now acquiring an enormous attention in the field of electric drive as well as in dynamic control due to its high dynamic response and its low cost. The vector controlled method is generally used due to its simplicity and fast response. The dynamic model of induction motor is precisely nonlinear, so having control over induction motor is a challenging problem which attracted much attention. Moreover, with the operation of the drives the parameters (resistance and inductance) vary due to saturation, skin effect or to variations in the temperature. In vector controlled induction motor drives the variation in inductance is negligible because it operates at constant flux, so the only resistance of the rotor and stator windings are variable. The performance of the drives influence by the variation of the resistances to omit this problem and improve the performance of the drive the controller scheme independent of the variation in parameters or developed some algorithm that can estimate and compensate the parameters simultaneously.

The rotor and stator resistance of induction motor vary with the temperature variation due to motor heating, many researchers develop an algorithm to predict the stator resistance [1] -[3] by using the microcontroller and online estimation but these are unstable in low speed range or the regenerative mode of the electric drives. Estimation of rotor

*E-mail address: ritu.tak@gmail.com

ISSN: $1791-2377$ C 2017 Eastern Macedonia and Thrace Institute of Technology. All rights reserved. doi:10.25103/jestr.106.02 resistance of the induction motor is important because strongly influences the speed of the induction motor. Rotor resistance estimated by using Reactive power error method, by torque error method and by error function based on stator voltage [4] -[7] these techniques take the large convergence time and a large harmonic present in the supply voltage that fluctuate the estimated parameters. Although all the above techniques estimate the stator or a rotor resistance individually where as the controller performance affects by variation of a stator and a rotor resistance both, so for improving the performance of the controller both stator and rotor resistance estimation require. In papers [8] -[10] both stator and rotor resistances are estimated, mainly used the online and observer based methods, these methods are complex it bounded the stator current. Fuzzy logic and artificial neural network are also used to estimate the rotor and stator resistance, but in this method proper design of fuzzy rules and the adjustment of the weight require [11] -[14]. Even many optimization methods like genetic algorithm, partial swam optimization methods are also used to estimate the resistance of the induction motor, but all these optimization methods are offline methods [15] -[18]. In the real world application any optimization technique requires a long time to run and a large memory and it is impossible to find exact result, the result can be only near the global extreme.

Sliding mode controller (SMC) is a robust controller, which is uncertain with the parameter variation. Most of the researchers use SMC observer for estimation the stator and rotor resistances [19]-[22] but they are higher order, due to this the complexity of the system increases. Even the 
classical SMC technique is also applied to estimate the resistance of the IM in the sensorless IM control drives [23]. The classical SMC faces the problem of chattering [24][25]. Many researchers work on to eliminate the chattering [26]. In recent years a robust software sensor for the IM drives is developed for estimation the stator resistance that improve the performance of the drives [27] but that software only estimate the stator resistance.

In this paper a second order SMC with the new proposed control law based on lyapunov stability theory [28] is used to estimate and also compensate the rotor and stator resistance, using online adaptation method. A singular perturbation theory is used to reduce the order of the induction motor from fifth order to second order [29]-[31] and the second order SMC in place of 9th or higher order decreases the complexity of the system and make it simple. The chattering problem is mitigates with the use of the second order SMC.

\section{Mathematical Modelling of Induction motor}

The Mathematical model of induction motor in the dq coordinate is given by [32].

$$
\frac{d}{d t}\left[\begin{array}{c}
i_{d s} \\
i_{q s} \\
\psi_{d r} \\
\psi_{q r}
\end{array}\right]=
$$$$
\left[\begin{array}{cccc}
-a_{1} & \omega_{e} & a_{2} & a_{3} \omega_{r} \\
-\omega_{e} & -a_{1} & a_{3} \omega_{r} & a_{2} \\
a_{5} & 0 & -a_{4} & \omega_{s l} \\
0 & a_{5} & -\omega_{s l} & -a_{4}
\end{array}\right]\left[\begin{array}{c}
i_{d s} \\
i_{q s} \\
\psi_{d r} \\
\psi_{q r}
\end{array}\right]+\left[\begin{array}{cc}
c & 0 \\
0 & c \\
0 & 0 \\
0 & 0
\end{array}\right]\left[\begin{array}{l}
v_{d s} \\
v_{q s}
\end{array}\right]
$$

$T_{e}-T_{L}=J \frac{d \omega_{m}}{d t}+B \omega_{m}$

where $\left(i_{d s}, i_{q s}\right),\left(v_{d s}, v_{q s}\right),\left(\psi_{d r}, \psi_{q r}\right)$ are stator current, stator voltage, and rotor flux respectively, these are normalized by the mutual inductance $L_{m}$ in $d q$ coordinate. Whereas $\omega_{r}, T_{e} T_{L}$ and $\omega_{e}$ is the. is rotor speed $(\mathrm{rad} / \mathrm{s})$, motor torque $(\mathrm{Nm})$, load torque $(\mathrm{Nm})$ and angular frequency of the stator current $(\mathrm{rad} / \mathrm{s})$ respectively.

Where,

$a_{1}=\frac{1}{\sigma L_{s}}\left(R_{s}+R_{r} L_{m}^{2} / L_{r}^{2}\right)$

$a_{2}=\frac{1}{\sigma L_{s}} R_{r} L_{m}^{2} / L_{r}{ }^{2}$

$a_{3}=\frac{1}{\sigma L_{s}} L_{m} /_{L_{r}} ; a_{5}=R_{r} L_{m} / L_{r} ; a_{4}=R_{r} /_{L_{r}} ;$

$c=\frac{1}{\sigma L_{s}}$

$\omega_{s l}=\omega_{e}-\omega_{r} ; \omega_{s l}=a_{5} \frac{i_{q s}}{\psi_{d r}}$

are constants, $R_{s}$ is the stator resistance, $R_{r}$ is the rotor resistance, $L_{s}$ is the stator inductance, $L_{r}$ is the rotor inductance, $L_{m}$ is the mutual inductance, $p$ is the number of poles pairs, and $J$ is the moment of inertia of the rotor.

As we can see from equation (1) and (2), the mathematical equation of induction motor is nonlinear and it is the fifth order of equations, in which many variables are known. To make a system simpler a singular perturbation theory is used to reduce the order of the induction motor [29-31]. According to that theory the part of the system which operated at slower speed assume as constant. In induction motor drive system the mechanical dynamics operated at much slower speed as compare to the current dynamics and electromagnetic dynamics. So, the flux and rotor speed assumed to be constant and drive the state space equation of the induction motor as given in equation (4). The order of the equation reduces to second order in which the states of the equations are only the d-axis stator and qaxis stator currents.

$\frac{d}{d t}\left[\begin{array}{l}i_{d s} \\ i_{q s}\end{array}\right]=$

$\left[\begin{array}{cccc}a_{1} & \omega_{e} & a_{2} & a_{3} \omega_{r} \\ -\omega_{e} & a_{1} & -a_{3} \omega_{r} & a_{2}\end{array}\right]\left[\begin{array}{c}i_{d s} \\ i_{q s} \\ \psi_{d r} \\ \psi_{q r}\end{array}\right]+$

$\left[\begin{array}{ll}c & 0 \\ 0 & c\end{array}\right]\left[\begin{array}{l}v_{d s} \\ v_{q s}\end{array}\right]$

In field orientated control of induction motor, to achieve field orientation, the q-axis torque component perpendicular to the rotor flux, and the d-axis flux component aligned in the direction of it. At this condition:

$\psi_{q r}=0$ and $\psi_{d r}=\psi_{r}=L_{m} i_{d s}$

Let the two control parameters $u_{1}$ and $u_{2}$ define as given below that can simply the equation

$u_{1}=-\frac{R_{s}}{\sigma L_{s}}$ and $\quad u_{2}=\frac{R_{r}}{L_{r}} L_{m}$

Therefore the eqns. (5) become

$\frac{d}{d t} i_{d s}=u_{1} i_{d s}+u_{2} \frac{i_{q s}^{2}}{\psi_{d r}}+\omega_{r} i_{q s}+\frac{v_{d s}}{\sigma L_{s}}$

$\frac{d}{d t} i_{q s}=u_{1} i_{q s}-u_{2} \frac{i_{q s}}{\sigma L_{m}}-\frac{\omega_{r}}{\sigma} i_{d s}+\frac{v_{q s}}{\sigma L_{s}}$

As from equation (6) that the rotor and stator resistances estimated by the control parameters $u_{1}$ and $u_{2}$. After estimation the resistances are compensated by the controller.

\section{Proposed Sliding Mode Controller Design}

The controller is design to finds the control parameters $u_{l}$ and $u_{2}$ in such a way that the error arises between an actual and estimated values of $\mathrm{d}$-axis and q-axis stator currents will be zero. The estimated currents are obtained from eqns. (7) and (8) as given below.

$$
\begin{aligned}
& \dot{\hat{\mathrm{i}}}_{d s}=\hat{u}_{1} \hat{\mathrm{i}}_{d s}+\hat{u}_{2} \frac{\mathrm{i}_{q s}^{2}}{\psi_{d r}}+\omega_{r} \hat{\mathrm{i}}_{q s}+\frac{v_{s d}}{\sigma L_{s}} \\
& \dot{\hat{\mathrm{i}}}_{q s}=\hat{u}_{1} \hat{\mathrm{i}}_{q s}-\hat{u}_{2} \frac{\mathrm{i}_{q s}}{\sigma L_{m}}-\frac{\omega_{r}}{\sigma} \hat{\mathrm{i}}_{d s}+\frac{v_{s d}}{\sigma L_{s}}
\end{aligned}
$$

The sliding mode controller operated in such a way that the error " $e$ " as well as its rate of change of $\dot{e}$ move towards a sliding surface. Sliding surface can be obtained by the use of lyapunov stability theory. 
Lyapunov stability theorem: It states that, if the projection of the system trajectories on sliding surfaces remains stable then the system is also stable. Thus the theorem can be formulated as:

Theorem: if a scalar function $V(x)$ is exist which is real, continuous and has continuous first partial derivatives with $V(x)>0$ for $x \neq 0 ; V(0)=0$

And its derivative $\dot{V}(x)$ is negative everywhere except the discontinuity surface then, the system is stable.

There is no specific method to find the Lyapunov function. However, V.I. Utkin[33] has discussed the method of using quadratic forms to find the sliding domain.

Generally, lyapunov function choose as $V=\frac{1}{2} e^{T} e$ where,

$e=\left[\begin{array}{l}\mathrm{i}_{d s}-\hat{\mathrm{i}}_{d s} \\ \mathrm{i}_{q s}-\hat{\mathrm{i}}_{q s}\end{array}\right]$

$\dot{V}=e^{T} \dot{e}=e^{T}\left[\begin{array}{l}\dot{\mathrm{i}}_{d s}-\dot{\hat{\mathrm{i}}}_{d s} \\ \dot{\mathrm{i}}_{q s}-\dot{\hat{\mathrm{i}}}_{q S}\end{array}\right]$

Substituting the values of actual and estimated stator currents from equations (7), (8), (9) and (10), in equation (12) for obtaining the expression of $\dot{V}$

$\dot{V}=e^{T} \dot{e}=e^{T} A e+e^{T} B e_{u}$

where,

$$
\begin{gathered}
\dot{e}=\left[\begin{array}{cc}
u_{1} & \omega_{r} \\
-\frac{\omega_{r}}{\sigma} & u_{1}
\end{array}\right]\left[\begin{array}{l}
\mathrm{i}_{d s}-\hat{\mathrm{i}}_{d s} \\
\mathrm{i}_{q s}-\hat{\mathrm{i}}_{q s}
\end{array}\right]+\left[\begin{array}{ll}
\hat{\mathrm{i}}_{d s} & \frac{\mathrm{i}_{q s}^{2}}{\psi_{d r}^{*}} \\
\hat{\mathrm{i}}_{q s} & \frac{\mathrm{i}_{q s}}{\sigma L_{m}}
\end{array}\right]\left[\begin{array}{l}
u_{1}-\hat{u}_{1} \\
u_{2}-\hat{u}_{2}
\end{array}\right] \\
A=\left[\begin{array}{cc}
u_{1} & \omega_{r} \\
-\frac{\omega_{r}}{\sigma} & u_{1}
\end{array}\right], B=\left[\begin{array}{ll}
\hat{\mathrm{i}}_{d s} & \frac{\mathrm{i}_{q s}^{2}}{\psi_{d r}^{*}} \\
\hat{\mathrm{i}}_{q s} & \frac{\mathrm{i}_{q s}}{\sigma L_{m}}
\end{array}\right], e_{u}=\left[\begin{array}{l}
u_{1}-\hat{u}_{1} \\
u_{2}-\hat{u}_{2}
\end{array}\right]
\end{gathered}
$$

$$
\text { Let us assume that }\left[\begin{array}{l}
\mathrm{i}_{d s}-\hat{\mathrm{i}}_{d s} \\
\mathrm{i}_{q s}-\hat{\mathrm{i}}_{q s}
\end{array}\right]=\left[\begin{array}{l}
e \mathrm{i}_{d s} \\
e \mathrm{i}_{q s}
\end{array}\right]
$$

As per the Lyapunov stability theorem, $\dot{V}$ is negative everywhere for the stability of the system. The first term in equation (14) is negative as the $A$ matrix is negative definite and the second term prove to be negative, which is given by

$e^{T} B e_{u}=\left[\begin{array}{ll}e \mathrm{i}_{d s} & e \mathrm{i}_{q s}\end{array}\right]\left[\begin{array}{ll}\hat{\mathrm{i}}_{d s} & \frac{\mathrm{i}_{q s}^{2}}{\psi_{d r}^{*}} \\ \hat{\mathrm{i}}_{q s} & \frac{\mathrm{i}_{q s}}{\sigma L_{m}}\end{array}\right]\left[\begin{array}{l}u_{1}-\hat{u}_{1} \\ u_{2}-\hat{u}_{2}\end{array}\right]$

The problem of tracking is similar to the remaining sliding surface for all time, and sliding variable is kept zero. We choose the sliding surfaces such that $e^{T} B e_{u}=0$.

Switching surface is a line in second order system. Control input is applied to drive the system state over the switching line, and at once the system is constrained to remain on the line. For deciding the control input, two parameters are used i.e. the distance of an error trajectory from the sliding surface and also its rate of convergence. The sign of the control input must change where the tracking error trajectory intersect with the sliding surface. In this way, the error trajectory is enforced to always move towards the sliding surface. Once it arrives at the sliding surface then, the system is constrained to slide along this surface to the equilibrium point. For estimation of $u_{1}$ and $u_{2}$ the sliding surface $S_{I}$ and $S_{2}$ is selected as given below respectively.

$s=\left[\begin{array}{l}S_{1} \\ s_{2}\end{array}\right]=\left[\begin{array}{c}e \mathrm{i}_{d s} \hat{\mathrm{i}}_{d s}+e \mathrm{i}_{q s} \hat{\mathrm{i}}_{q s} \\ e \mathrm{i}_{d s} \frac{\mathrm{i}_{q s}^{2}}{\psi_{d r}^{*}}-e \mathrm{i}_{q s} \frac{\mathrm{i}_{q s}}{\sigma L_{m}}\end{array}\right]$

The main drawback of the sliding mode controller (SMC) in real time application is the chattering problem to remove or reduce the chattering in the control, the order of the controller must be greater than one. In the proposed algorithm a Quasi second order SMC is choose because it provides the continuous control everywhere except the manifold, as a result the chattering effect reduces.

A Quasi second order SMC, provides the full SISO control based on the input measurement only. The homogeneous differentiator can be defined as [34].

$\left.\dot{z_{o}}=-\lambda_{\delta} L^{1 / \delta} \cdot \dot{z_{o}}-\left.s\right|^{(\delta-1) / \delta}\right) \operatorname{sign}\left(z_{0}-s\right)+z_{1}$

$\dot{z}_{\delta-1}=-\lambda_{1} \operatorname{Lsign}\left(z_{\delta-1}-\dot{z}_{o}\right)$

where $\delta$ is the order of the system. As from equation (4) the order of the system is second; $\delta=2$ means the first derivative of the $s$ is need.

As

$\delta=2$,

$\dot{z_{o}}=-\lambda_{2} L^{1 / 2}\left|z_{o}-s\right|^{(1 / 2)} \operatorname{sign}\left(z_{0}-s\right)+z_{1}$

$\dot{z}_{1}=-\lambda_{1} \operatorname{Lsign}\left(z_{1}-\dot{z}_{o}\right)$

Where $\lambda_{2} L^{1 / 2}$ and $\lambda_{1} L$ are positive constant and $\dot{s}=z_{1}$. The differentiator in equation (19) is used to derived the second order sliding homogeneous control signals is obtained as

$\dot{\hat{u}}=-\alpha\left(\dot{s}+|s|^{1 / 2} \operatorname{sign}(s)\right) /\left(\left.|\dot{s}+| s\right|^{1 / 2} \mid\right)$

Where and $\alpha$ is a positive constant.

By integrating the equation (20) we get the estimated values of the control parameter and indirectly the stator and rotor resistances.

The proposed algorithm is uncertain with the parametric variations of the system and due to the higher order, high frequency noise is also reduces. The block diagram of the proposed algorithm is shown in figure 1.

\section{Simulation and Result}

The Matlab/Simulink, is used to simulated the proposed controller. The simulation model and the results are presents in this section. Table 1 specified the machine parameters which are used in the simulation. The figure 2 shows the overall simulink model of the proposed controller with induction motor. There are four subsystems in this model 
Ritu Tak, Sudhir Y Kumar and Bharat Singh Rajpurohit/Journal of Engineering Science and Technology Review 10 (6) (2017) 9-15

out of which one is the vector control block, the interior of this subsystem is shown in figure 3 from this simulink block generated the control pulse for the inverter. The second one is the subsystem 1 shown in figure 4 from this the sliding surface for the sliding mode controller is generated, according to this sliding surface the two control signal $u_{1}$ and $u_{2}$ by using equation (20) form, the simulink block of this is shown in figure 5 . These control signals signifies the estimated values of stator and rotor resistance as shown by the equation (6). The other subsystem in the main simulink model is the subsystem 3 that represent the control unit of the proposed system. The interior of the subsystem 3 is representing in figure 6.

Table 1. Induction motor parameters

\begin{tabular}{c|c|c}
\hline Parameter & Notation & Value \\
\hline Rotor resistance & $\mathrm{R}_{\mathrm{r}}$ & $4.3047 \Omega$ \\
Stator resistance & $\mathrm{R}_{\mathrm{s}}$ & $6.65 \Omega$ \\
Mutual inductance & $\mathrm{L}_{\mathrm{m}}$ & $0.4475 \mathrm{H}$ \\
Stator inductance & $\mathrm{L}_{\mathrm{s}}$ & $0.4718 \mathrm{H}$ \\
Rotor inductance & $\mathrm{L}_{\mathrm{r}}$ & $0.4718 \mathrm{H}$ \\
Rotor inertia & $\mathrm{J}$ & $0.0293 \mathrm{~kg} / \mathrm{m}^{2}$ \\
Pole pair & $\mathrm{p}$ & 2 \\
\hline
\end{tabular}

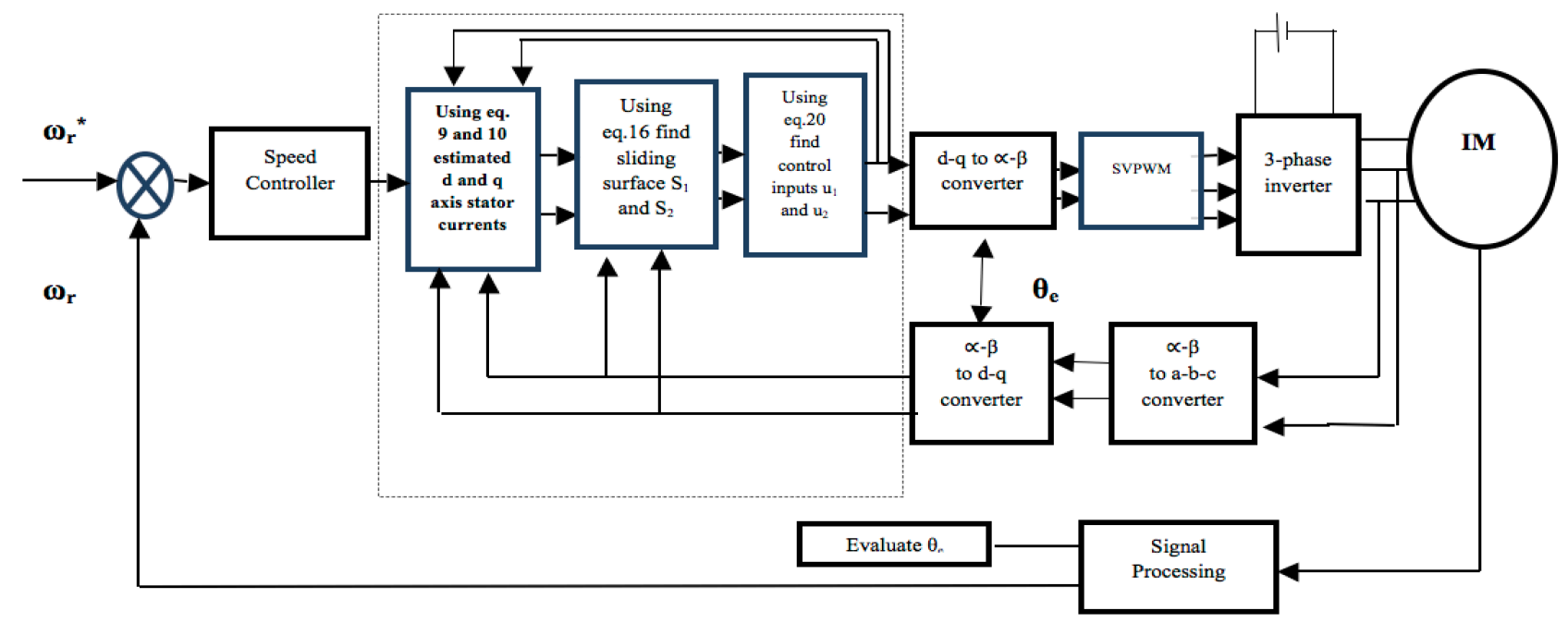

Fig.1 Block Diagram with Proposed Algorithm

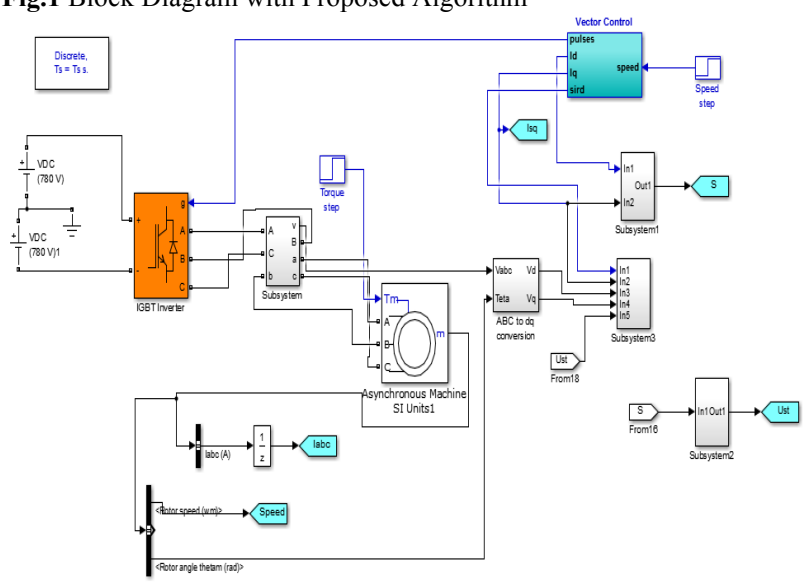

Fig. 2. Simulation Model of Induction motor with proposed controller

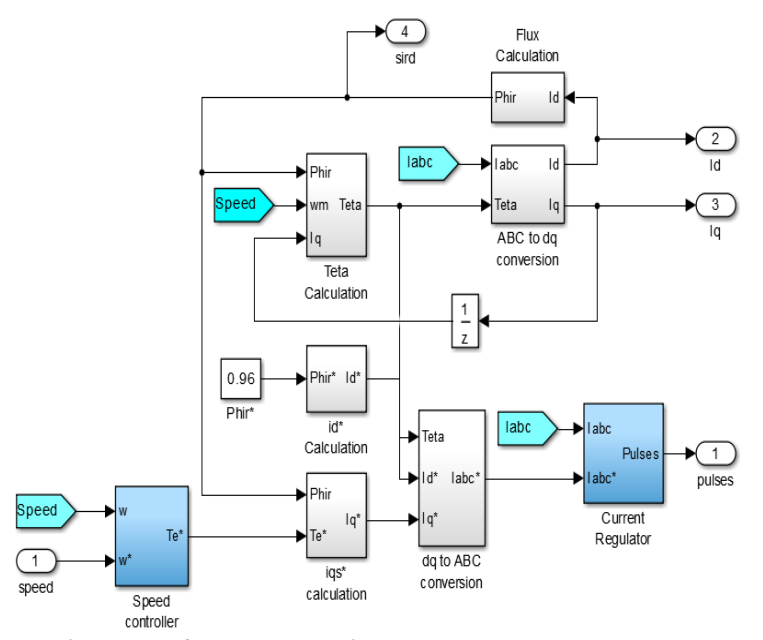

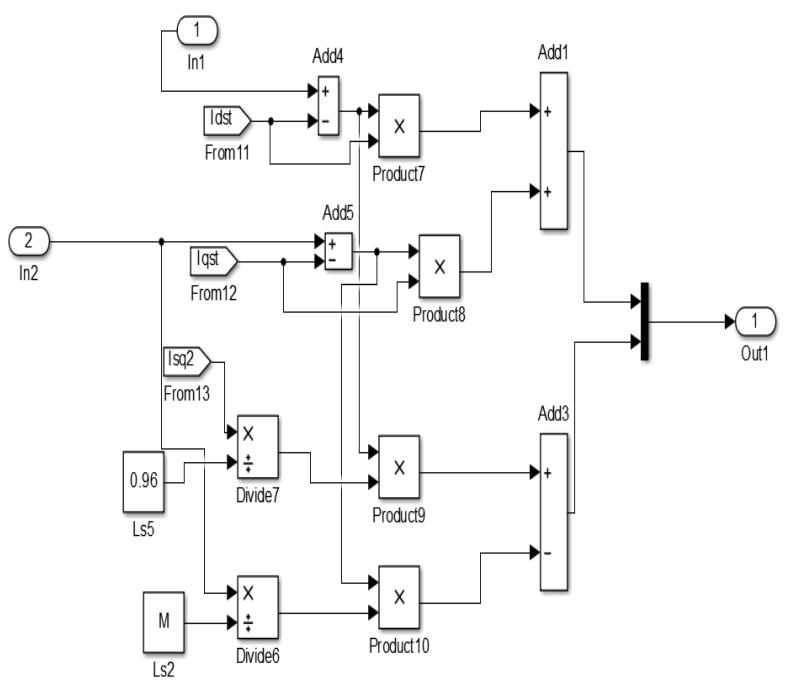

Fig. 4. Subsystem 1 of sliding surface $S$

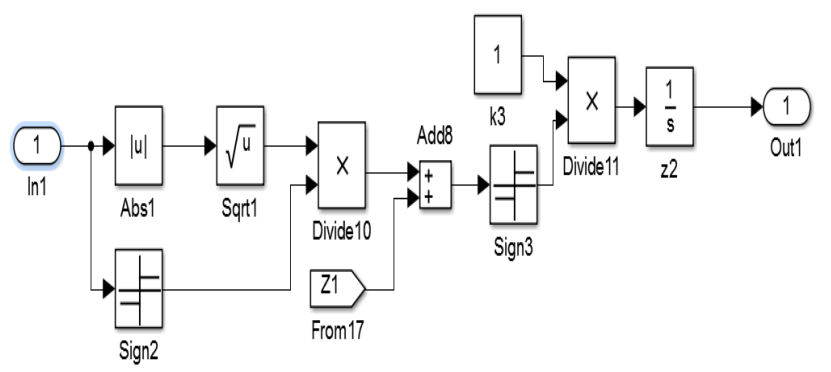

Fig. 5. Subsystem 2 for control parameter $u_{1}$ and $u_{2}$

Fig. 3. Subsystem of Vector control 


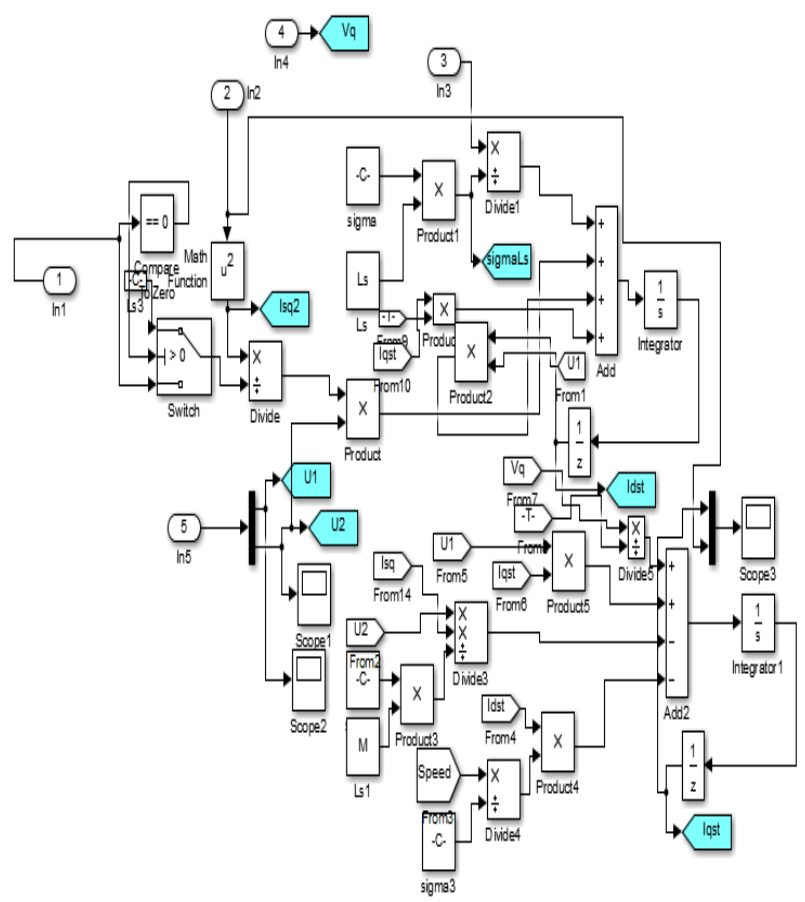

Fig. 6. Subsystem 3 control block

The induction motor is run under a constant speed of let it be $30 \mathrm{rad} / \mathrm{s}$ and after a $2 \mathrm{sec}$. a load torque of $2 \mathrm{Nm}$ is applied during this time the flux is established and attain a constant value in the machine. As observed from figure 7 and 8 the sliding surface $S_{1}$ and $S_{2}$ are reached then they are maintained even the parameters of the machines changed. By using estimated values of the control signal $u_{1}$ and $u_{2}$ as shown in figure 9 and 10 respectively, the values of stator and rotor resistances is calculated. As the estimated resistance values reach the actual on the sliding surfaces are reached they are maintained their irrespective of parameter variation. The estimated and actual values of the stator $d$ and $\mathrm{q}$ axis currents showed in figure $11,12,13$ and 14 . The sliding surface not altered after reached, that certify the proposed method for compensation and estimation of machine parameters.

As seen from figure 7 and 8 the sliding surface are reached within 0.05 seconds means within a fraction of seconds the proposed algorithm estimate and compensate the rotor and stator resistance to their actual one where as the optimization techniques take a lot time and not give the accurate results. Even the Practical swarn optimization using online adaptation not give the quit accurate results in the fraction of time.

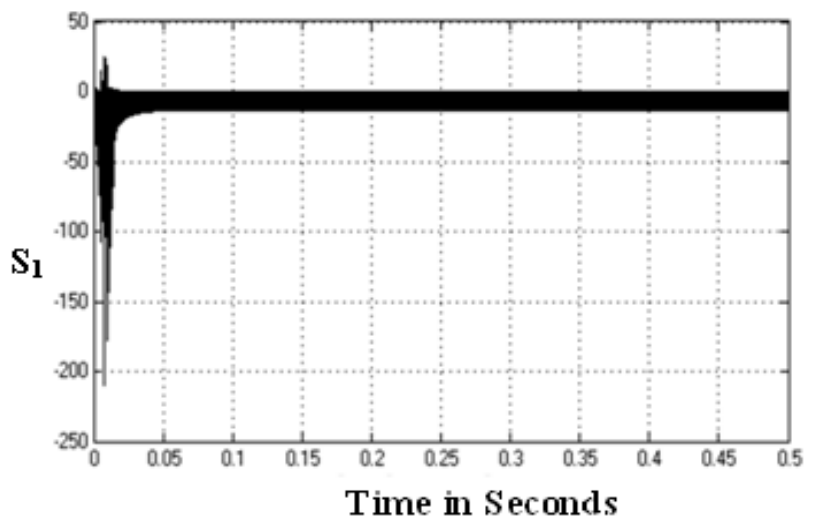

Fig. 7. The Sliding Surface $S_{l}$

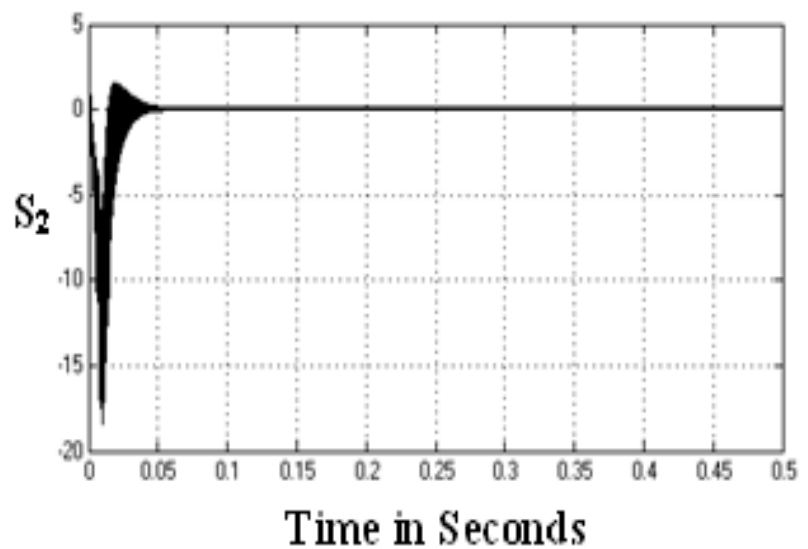

Fig. 8. The Sliding Surface $S_{2}$

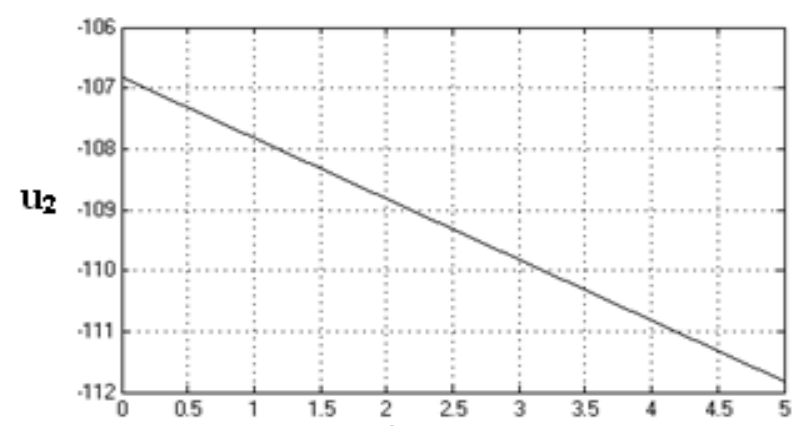

Time in Seconds

Fig. 9. Estimated value of $u_{2}$

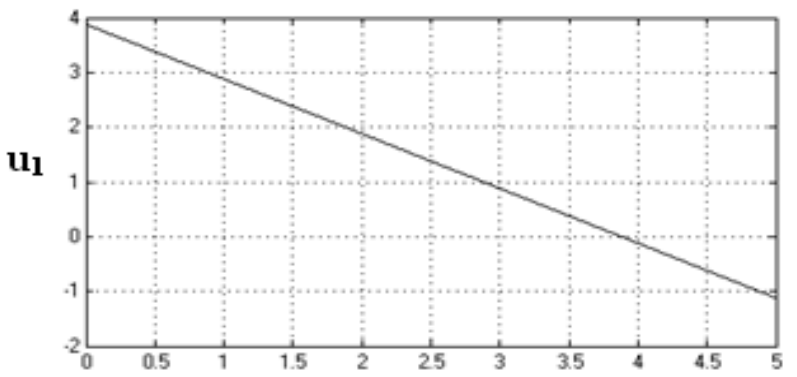

Time in Seconds

Fig. 10. Estimated value of $u_{I}$

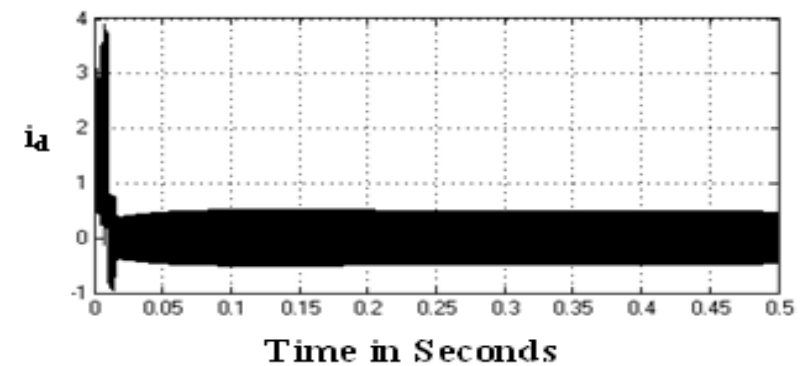

Fig. 11. Actual d-axis stator current

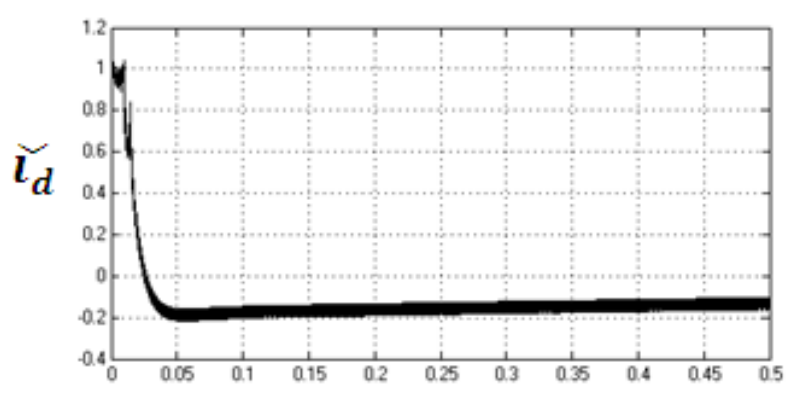

Time in Seconds

Fig. 12. Estimated value of d-axis current 


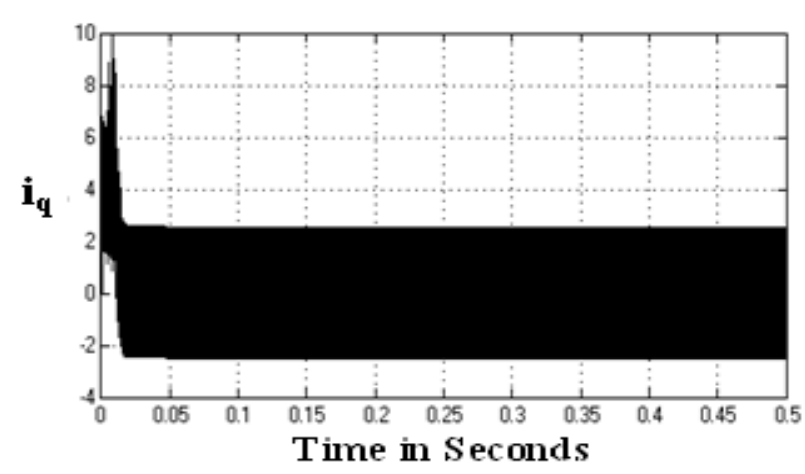

Fig. 13. Actual q-axis stator current

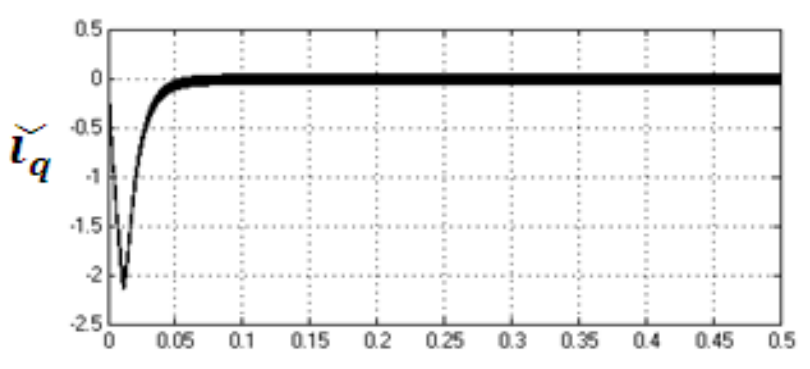

Time in Seconds

\section{Conclusion}

A new algorithm using sliding mode control technique for induction motor parameters rotor and stator resistance estimation and compensation is proposed in this paper. The simulation done in Matlab/Simulink, the result shows the effectiveness of the proposed method. The proposed algorithm provides high dynamic response as the result analysis the system reach the sliding surface within 0.1 second and maintain their even the variation in resistances this shows the robustness of the method and the control signals $u_{1}$ and $u_{2}$ estimate as well as compensate $R_{l}$ and $R_{2}$ within 5 seconds that makes it better than other method of parameter compensation in induction motor. In the proposed algorithm assumed that the inductance is constant even the inductance also vary when the motor operates, in future the estimation and compensation of inductance also included in the proposed algorithm.

This is an Open Access article distributed under the terms of the Creative Commons Attribution Licence

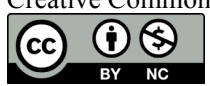

Fig. 14. Estimated value of $q$-axis current

\section{References}

1. R. Krishnan and A. Bharadwaj, "A review of parameter sensitivity and adaptation in indirect vector controlled induction motor drive systems,'IEEE Trans. Power Electron., vol. 6, no. 4, pp. 695-703, Oct. 1991.

2. M. Zaky, "Stability analysis of speed and stator resistance estimators for sensorless induction motor drives," IEEE Trans. Ind. Electron., vol. 59, no. 2, pp. 858-870, Feb. 2012.

3. Y. Xu, N. Parspour, and U. Vollmer, "Torque ripple minimization using online estimation of the stator resistances with consideration of magnetic saturation," IEEE Trans. Ind. Electron., vol. 61, no. 9, pp. 5105-5114,Sep. 2014.

4. Faiz J.and Sharifian,M. B. B., "Different techniques for real time estimation of an induction motor rotor resistance in sensorless direct torque control for electric vehicle", IEEE Trans. Energy Conversion, vol. 16, pp. 104-109, Mar.2001.

5. David Diaz Reigosa, Fernando Briz, Cristian Blanco Charro, Antonio Di Gioia, Pablo Garcia, Juan Manuel Guerrero, "Sensorless Control of Doubly Fed Induction Generators Based on Rotor High-Frequency Signal Injection", IEEE Transactions on Industry Applications, vol.49, Issue 6, 2013

6. K. Wang, B. Chen, G. Shen, W. Yao, K. Lee, and Z. Lu, "Online updating of rotor time constant based on combined voltage and current mode flux observer for speed-sensorless ac drives," IEEE Trans. Ind. Electron., vol. 61, no. 9, pp. 4583-4593, Sep. 2014.

7. Avanish Tripathi, V.S.S. Pavan Kumar Hari, G. Narayanan, "Closed-loop rotor flux estimation in vector controlled induction motor drives operated at low switching frequencies", IEEE International Conference on Power Electronics, Drives and Energy Systems, May 2017.

8. Jakub Talla, Zdenek Peroutka, Vojtech Blahnik, Lubos Streit, "Rotor and stator resistance estimation of induction motor based on augmented EKF" ,IEEE International Conference on Applied Electronics , 2015

9. R. Marino, S. Peresada , P. Tomei ,"On-line stator and rotor resistance estimation for induction motors", IEEE Transactions on Control Systems Technology, vol.8, Issue 3, May 2000.

10. Seok Ho Jeon, Kwang Kyo Oh, Jin Young Choi, "Flux observer with online tuning of stator and rotor resistances for induction motors" , IEEE Transactions on Industrial Electronics, vol.49, Issue 3, Jun 2002

11. Venkadesan Arunachalam, Himavathi Srinivasan, A.Muthuramalingam, "A novel NN based rotor flux MARS to overcome low speed problems for rotor resistance estimation in vector controlled IM drives." Frontiers in Energy, vol.10, Issue 4, pp 382-392, Dec.2016.

12. Baburaj Karanayil, Muhammed Fazlur Rahman, and Colin Grantham, "Online Stator and Rotor Resistance Estimation Scheme Using Artificial Neural Networks for Vector Controlled Speed Sensorless Induction Motor Drive", IEEE Transactions On Industrial Electronics, vol. 54, No. 1, February 2007.

13. Murat Sonmez; Mehmet Yakut, "Identification of IM Resistance Using Artificial Neural Network in Low Speed Region" International Conference on Intelligent Sensors, Sensor Networks and Information, 2007.

14. B. Karanayil, M.F. Rahman, C. Grantham, "Stator and Rotor Resistance Observers for Induction Motor Drive Using Fuzzy Logic and Artificial Neural Networks", IEEE conference on Industry Applications, Oct. 2003.

15. P. Castaldi and A. Tilli, "Parameter estimation of induction motor at standstill with magnetic flux monitoring," IEEE Transactions on Control Systems Technology, vol. 13, no. 3, pp. 386-400, 2005.

16. Hamid Reza Mohammadi, Ali Akhavan, "Parameter Estimation of Three-Phase Induction Motor Using Hybrid of Genetic Algorithm and Particle Swarm Optimization", Journal of Engineering Vol. 2014.

17. Ritwik Giri, Aritra Chowdhury, Arnob Ghosh, B. K. Panigrahi, Swagatam Das, "Offline Parameter Estimation of Induction Motor Using a Meta Heuristic Algorithm" Swarm, Evolutionary, and Memetic Computing pp 523-530, 2010.

18. D.C.Huyuh, Matthew W. Dummigan, "Parameter Estimation of an Induction Machine using a Dynamic Particle Swarm Optimization Algorithm" IEEE conference on Industrial Electronics, August 2010.

19. Sergei Peresada; Sergei Kovbasa; Vladimir Trandafilov; Vladimir Pyzhov, "Sliding mode observer based control of induction motors: Experimental study" , IEEE International Conference on Intelligent Energy and Power Systems, 2014.

20. Chau Dong, Pavei Brandstetter, Huu Hau Vo, "Sliding Mode Observer for Induction Motor Control" , Recent Advances in electrical Engineering and related sciences, pp 313-323, March 2016.

21. Antonella Ferrara, Matteo Rubagotti, “A Sub-Optimal Second Order Sliding Mode Controller for Systems With Saturating 
Ritu Tak, Sudhir Y Kumar and Bharat Singh Rajpurohit/Journal of Engineering Science and Technology Review 10 (6) (2017) 9-15

Actuators" , IEEE Transactions on Automatic Control, vol. 54, No. 5, May 2009.

22. Shihong Ding, Arie Levant, Shihua Li, "New Families of HighOrder Sliding-Mode Controllers", IEEE 54th Annual Conference on Decision and Control (CDC), Dec. 2015.

23. Sachit Rao, Martin Buss, Vadim Utkin , "State and parameter estimation in induction motors using sliding modes", Power Electronics and Motion Control Conference, 2008.

24. Igor Boiko, Leonid Fridman, Alessandro Pisano, and Elio Usai, "Analysis of Chattering in Systems With Second-Order Sliding Modes IEEE Transactions on Automatic Control, vol. 52, no. 11, Nov. 2007.

25. Hua Meng; XiaoHong Zheng; JianHua Zhang "Research on chattering problem of sliding mode variable structure control in AC servo system" IEEE conference on Guidance, Navigation and Control, August 2016.

26. Khatir Khettab, Yassine Bensafia, Samir Ladaci, "Chattering Elimination in Fuzzy Sliding Mode Control of Fractional Chaotic Systems Using a Fractional Adaptive Proportional Integral Controller" , International Journal of Intelligent Engineering and Systems, vol.10, no.5,2017.

27. Omar Naifar, Ghada Boukettaya, Abderrazak Ouali, "Robust software sensor with online estimation of stator resistance applied to WECS using IM “, International Journal of Advanced
Manufacturing Technology, vol. 84, Issue 5-8, pp 885-894, May 2016.

28. Jeang-Lin Chang ,Shih-Yu Lin, Kuan-Chao, min-Shin Chen , "Lyapunov stability analysis of second order sliding mode control and its application to chattering reduction design", International Journal of Control Automation and System, vol.14, Issue 3 pp 691-697, June 2016.

29. Alireza Khayatian; Mehrnoosh Asadi, "Singular perturbation theory in control of nonlinear systems with uncertainties", IEEE Conference on Electrical Engineering, May 2016.

30. Hyungduk Seo, Donghoon Shin, Youngwoo Lee, Chung Choo Chung, " A simplified nonlinear control for sawyer motors based on singular perturbation theory" IEEE Conference on Control, Automation and Systems, Oct. 2014.

31. Yong Liu, J. Jim Zhu, " Singular Perturbation Analysis for Trajectory Linearization Control” , IEEE American Control Conference, July 2007.

32. B. K. Bose, Modern Power Electronics and AC Drives. New Delhi, India: Prentice Hall of India Private Limited, 2006.

33. V. Utkin, "Sliding mode control design principles and applications to electric drives," IEEE Trans. Ind. Electron., vol. 40, no. 1, pp. 23-36,Feb. 1993.

34. Arie Levant, "Quasi-continuous high-order sliding mode controller", Preceding of the 42th IEEE conference ondecision and control, USA, December 2003. 